\title{
Life Cycle Model for IT Performance Measurement: A Reference Model for Small and Medium Enterprises (SME)
}

\author{
Can Adam Albayrak ${ }^{1}$, Andreas Gadatsch ${ }^{2}$, and Dirk Olufs ${ }^{3}$ \\ ${ }^{1}$ Harz University of Applied Sciences \\ Friedrichstr. $57-59$ \\ 38855 Wernigerode, Germany \\ ${ }^{2}$ Bonn-Rhein-Sieg University of Applied Sciences \\ Grantham Allee 20 \\ 53757 Sankt Augustin, Germany \\ ${ }^{3}$ DHL Express Europe \\ De Kleetlaan, 1 \\ 1831 Diegem, Belgium
}

\begin{abstract}
IT performance measurement is often associated by chief executive officers with IT cost cutting although IT protects business processes from increasing IT costs. IT cost cutting only endangers the company's efficiency. This opinion discriminates those who do IT performance measurement in companies as a bean-counter. The present paper describes an integrated reference model for IT performance measurement based on a life cycle model and a performance oriented framework. The presented model was created from a practical point of view. It is designed lank compared with other known concepts and is very appropriate for small and medium enterprises (SME).
\end{abstract}

Keywords: IT management, SME, small and medium enterprises, reference model, process model.

\section{Introduction}

In business and administration we have witnessed a permanent change away from a technical view to a business orientation. In the seventies and eighties the electronic data processing was dominated by a rule based batch processing and automatisation of mass data oriented business processes (e.g. book-keeping, warehousing and salary statement). IT supported only selected business functions which were not integrated. IT costs were only covered by a central IT cost centre. There were no further calculations of business cost centres which have used the IT output (e.g. computing time, data space). During this time the status of the IT department was very exclusive. Only IT managers had access to external suppliers of hardware and software or to consulting companies. Real time software (e.g. ERP-Systems like SAPß R/3®) increasingly changed the traditional batch processing software. During the nineties, there were a lot of business process reengineering projects undertaken to remove legacy software 


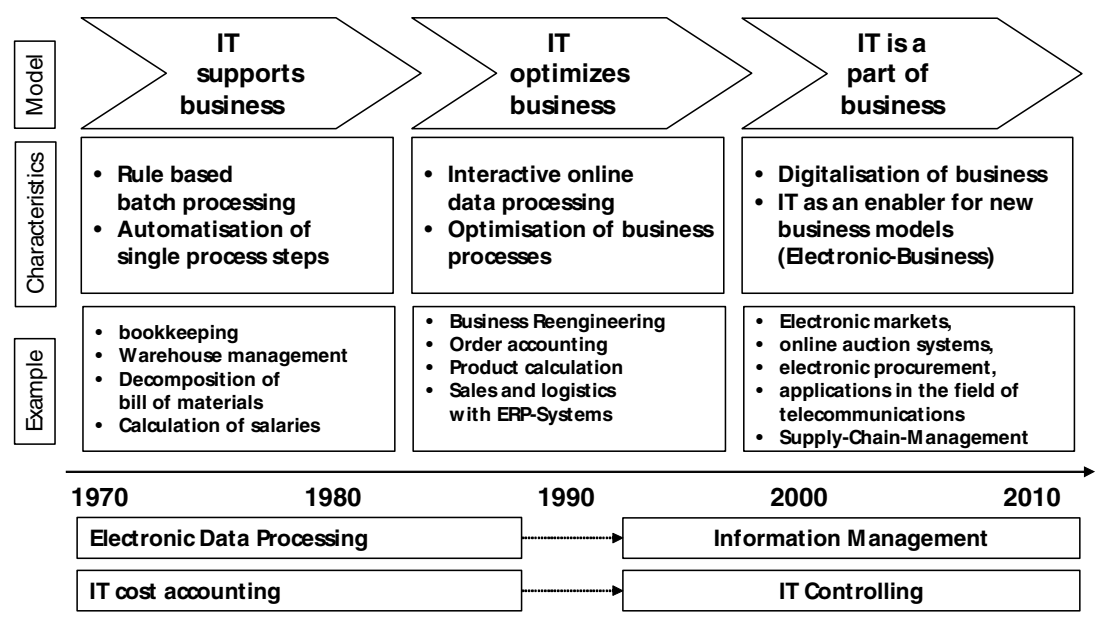

Fig. 1. From a technique to a business orientation

systems by changing business processes (Hammer and Champy 1994). The main aim in this age was to optimize the internal business processes by IT.

During the last decade, IT was identified as a weapon in competition and as an enabler for new business models. Electronic markets, online auction systems, electronic procurement, applications in the field of telecommunications or supply chain management were invented and further developed during this time.

As the latest information dating to the nineties indicates, information management has been used as a management tool to control the dominating technical oriented data processing. The head of information management is often called the head of IT but actually the chief information officer (CIO) is responsible for the fulfilment of the production factor information.

The acceptance of the production factor information can be seen by the grading of the $\mathrm{CIO}$ role inside of the companies. Often the $\mathrm{CIO}$ was a part of or has to report to the management board or was positioned a level below. A current overview of the personnel anchoring of the CIO role is described by Riedl et al. (2008).

Now, not only has the CIO role changed in companies, the role of the IT departments has also been changing dramatically. In former years, IT was classified as a cost factor only. In the current times, IT is more and more seen as a business partner and business enabler for generating strategic advantages (see fig. 2). This change of tenor has had repurcussions on the challenges and ranking of the IT performance measurement concept. However, business departments see the IT department not as an end in itself. They see it as a tool or service partner for business process support and to create added value for the company. Managers from business departments wield more influence to IT oriented decisions than in the seventies or in the eighties. IT is increasingly becoming an essential part of the business.

An extreme position while discussing the importance of IT was presented by Carr in his paper IT Doesn't Matter (Carr 2003) and later in more precise papers (Carr 2004). Carr states that IT has the similar significance like energy or other bulk goods. He doesn't see any strategic relevance. IT will be a commodity or a standardized bulk 

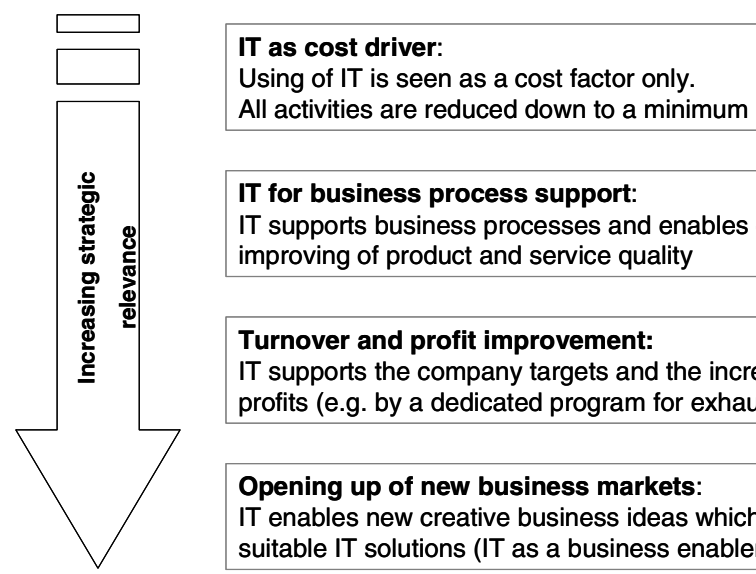

Turnover and profit improvement:

IT supports the company targets and the increasing of turnover and profits (e.g. by a dedicated program for exhaustion of a market)

\section{Opening up of new business markets:}

IT enables new creative business ideas which are not to operate without suitable IT solutions (IT as a business enabler)

Fig. 2. Increasing strategic relevance of the IT

good like electric power from a socket. Examples show that this opinion is not generally accepted. A lot of examples of companies like Amazon, Google, Dell and so on show us that the the production factor information enables business which is not possible without this factor. The processing and delivering of information in large amounts and high speed would not be possible without using IT. However IT is a strategic factor. Zarnekow and colleagues along with many other authors, describe how to manage the production factor information along the information life cycle (Zarnekow et al. 2006).

\section{IT Performance Measurement from a Current Perspective}

The term IT performance measurement is sometimes called IT controlling is interpreted in various ways. We do not want to give a nomenclature to those who do IT performance measurement, because the task of IT performance measurement can be done in different roles, even if the task list of the IT performance measurement in companies varies very strongly. In the following section we describe the main tasks in a context of IT performance measurement as an enabler for the IT management and as a main part of IT governance.

\subsection{IT Performance Measurement as an Enabler for the IT Management}

A very narrow opinion describes IT performance measurement as a cost inspector of the IT department which is placed below the board of management or inside of the IT department. This view is a partial definition of the duties, because it covers only cost and technical aspects. Such definitions are misleading and not adequate. Newer definitions see IT performance measurement as a tool for decision support by using IT resources. Becker and Winkelmann (2004) define IT performance measurement as purchasing, preparation and analysing of data to prepare target oriented decisions for purchase, realise and run hardware and software. Those who do IT performance 
measurement act as a service partner interface between company performance measurement and/or company controlling and management. They bridge communications and cultural barriers between technical and economic perspectives, and they contribute towards a better understanding and an adequate culture when using IT resources (GI 2008).

Different experiences often falsify the scope of duties of IT performance measurement. Cautioned by the increaseing cost pressure, IT performance measurement often is mistaken for cost cutting in the IT arena. One reason for this is the strong penetration of business processes within IT and the increased IT cost share. A lack of transparency of this cost pool leads to an impression of a necessity of cost reduction by the IT management.

The individuals who do IT performance measurement are in danger of being degraded to a cost cutter. A performance oriented view recognises that using IT is connected with performance enhancement and efficiency improvement. It is being more and more accepted that the IT department is not a manual worker but a core element for ensuring the competitiveness of a company. IT performance measurement supports the ability to deliver IT in companies.

The IT performance measurement have to work on an operational and strategic level. Schauer enumerates as strategic tasks: fixing of the IT strategy, IT budgeting, management of the IT portfolio and performance measurement of the benefits (Schauer 2006). Kütz defines for operational task the plan/current comparison for key performance indicators, the analysis of variances and the launching of correction activities (Kütz 2007).

There are different tools available to meet the challenges of operational and strategic IT performance measurement. The usage of the balanced scorecard (Kaplan and Norton 2001), benchmarking and IT portfolio management are assigned to the strategic level. Cost accounting, process modelling and reporting are tools for the operational level. Applications of the balanced scorecard as an IT performance measurement instrument can be found e.g. in (Bernroider et al. 2003), (Martinsons et al. 1999), (Müller et al. 2002) and many other publications.

\subsection{IT Performance Measurement as a Part of IT Governance}

The IT Governance Institute is a non profit organisation that is developing international IT standards for the planning and control of internal information systems. They define IT governance as a main target to foster understanding of the strategic relevance of IT in optimiing the company's targets and strategies for future enhancement of business operations (IT Governance Institute 2008). Weill and Ross (2004) defines IT governance as "the decision rights and accountability framework for encouraging desirable behaviours in the use of IT". Meyer and his co-authors give an overview on IT governance in (Meyer et al. 2003). Van Grembergen and his co-authors (2004) consider IT governance more inside of the context of temporary orientation and business process orientation. According to their definition IT governance is more than IT management, which has a strong internal orientation to the entity. IT governance is more externally oriented and more strongly adjusted to the future but not as intense as a long term IT strategy. 


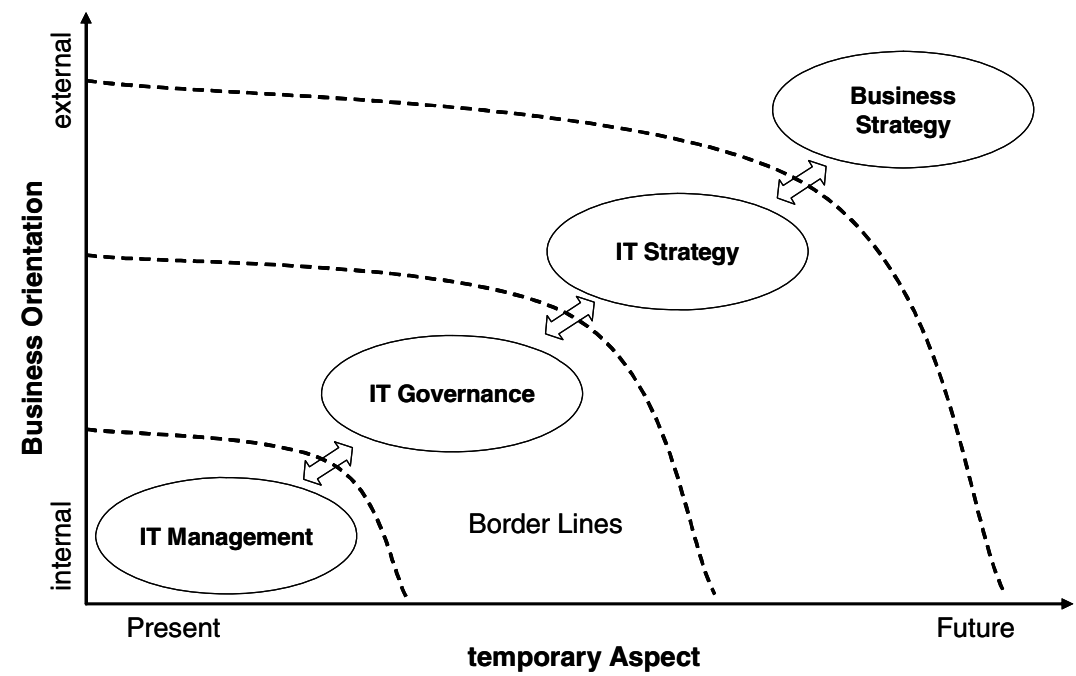

Fig. 3. Classification of IT management and IT governance, according to (van Grembergen et al. 2004)

The authors of this paper agree with CobiT (CobiT 2008) that IT governance is the management function of the IT department following the pretend framework. The target of IT governance is to align all activities of the IT department continuously to the company's targets and business processes (IT business alignment). IT governance has to follow the following restrictions: Sustainable and gentle usage of IT resources (resource management), minimizing IT risks (IT risk management) and following law, rules and IT standards (IT compliance). We consider IT performance measurement as both: as a part of IT management and as a part of IT governance.

\section{Reference Model for IT Performance Measurement}

In this chapter we first take a short look at known reference models. Then we present our new reference model for small and medium enterprises (SME).

\subsection{Reference Models for IT-Performance Measurement}

According our declarations in the chapter above, IT performance measurement supports IT management and the IT governance. Following this we divide these into known reference models for the IT management process and the IT governance process.

There are some standard reference models for IT governance. One of the most important standard models is CobiT (Control Objectives for Information and related Technologies) from the IT Governance Institute (ITGI). The ITGI emphasises that CobiT is a tool for the strategic reengineering process which is compatible with other standard process models. 
CobiT keeps their main focus on the IT life cycle viewed by the process owner of the relevant IT processes. CobiT divides into control area, planning and organisation, procurement and implementation, running and operations and supervising of 34 IT processes. For every one of the 34 main processes, CobiT formulates specific control targets to ensure the support of the business processes. The central criteria are efficiency of quality, integrity, trust and availability of safety. The level of fulfilling the criteria is measured on a scale within 0 , which means not existing and 5 , which means optimised (Cobit 2008 and IT Governance Institute 2008).

Likewise, there are a lot of reference models for IT management processes. We only mention some examples. For IT service management ITIL is well known in practice as a commonly accepted best practice model. For maturity level in software engineering we recommend CMMI and for implementing and running of IT management systems, we mention the Standard Security Framework ISO 17799 (now ISO 27001). CobiT integrates ITIL and ISO 9000 for quality management, CMMI and ISO 17799 by compatibility of CobiT with these models.

\subsection{IT Process Model for SME}

Small and medium enterprises (SME) are characterized by simple structures, high flexibility and a high sensitivity in costs. The consequences are at a lower significance in IT management and very tall processes compared to bigger companies. A standard process model like CobiT with 34 main chapters is too complex for use in SME's.

Hence we present an IT process model for SME's first which is oriented as a life circle for IT investments. When we take a look at the processes planning, development and running of IT applications, we see the following sub processes as depicted in fig. 4.
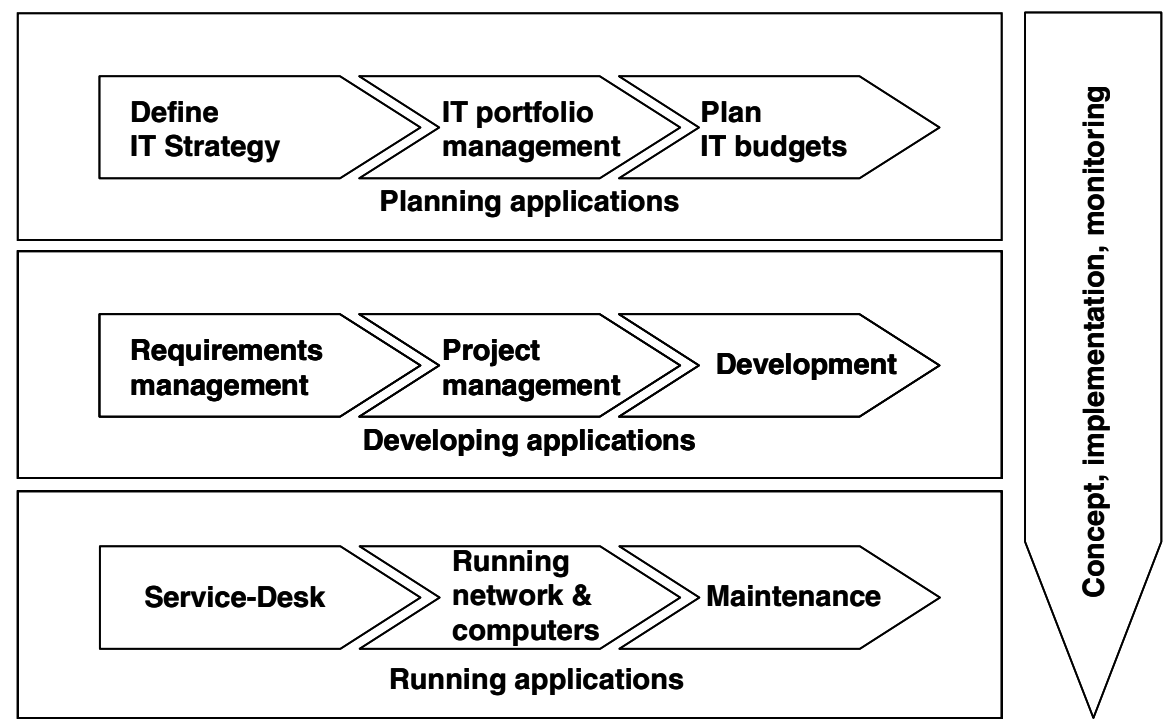

Fig. 4. Planning, developing and running of IT applications 
The process of developing applications starts with the investigation of the requirements which have to be transformed into existing or new IT applications. The project manager ensures the smooth execution of the projects using dedicated methods for project management. The development of software or customization of standard software is supported by the IT department.

After the roll out of the software packages, the process running applications is following. First there are activities to build up the IT infrastructure e.g. data centre, network, desk top computers. Following this is the maintenance of applications. Requests of end users are supported by the service desk. All tasks are run through the phases of the life cycle concept, implementing and monitoring, where the IT performance management has to be involved. There is no clear dividing line between the strategic and operational IT performance measurement. Inside the process planning applications, a comprehensive IT strategy has to be designed. The IT strategy should cover the implementation and monitoring of IT oriented projects to reach the companies targets.

The main content of an IT strategy comprises:

1. Transparency of the starting point (Where are we now? See possible questions in table 1)

2. Defining the future situation (Where do we want to be?)

3. Describing the strategic gap (What do we have to do? Where are the weaknesses?)

4. Identifying of alternatives for actions? (Which choices do we have?)

5. Adjustment with business departments? (IT business alignment- Does everybody agree to our strategy?)

6. Setting of targets and defining of tasks (What has to be done concretely? Until when do we have to reach our targets?)

7. Arranging the responsibility (Who is responsible for the tasks?)

8. Assigning of indicators for the target monitoring (When do we know we have reached the targets?)

The partial strategies for each IT department can be seen in Fig. 5.

Table 1. Questions to identify the initial situation

1. Which applications or data base systems are in use currently?

2. Which IT infrastructure (e.g. hardware) is in use?

3. Which IT projects or business projects with IT aspects are enabled?

4. How is the IT department organised?

5. Which standard business processes and IT processes are available?

6. Which known IT risks really do exist?

7. What are the targets and contents of the former IT strategy?

The quantifying of IT projects is supported by methods of investment appraisals and non monetary criteria in cooperation with the IT performance measurement. This ensures that an IT project portfolio is compliant to the IT strategy. The IT performance measurement is responsible for the coordination of the process of planning the IT budgets. 


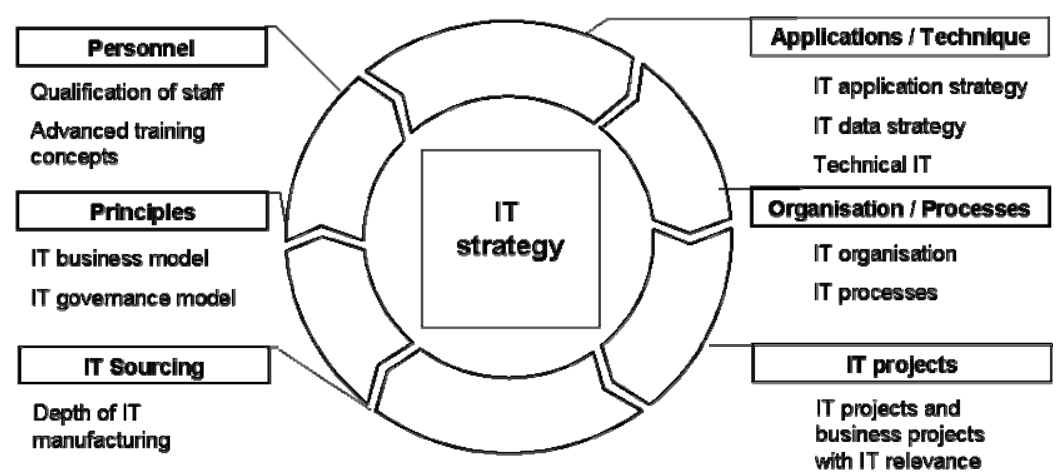

Fig. 5. Partial IT strategies

\subsection{Life Cycle Model for SME}

A life cycle model is necessary for planning, implementing, analysing and maintenance of IT services, IT processes, IT application systems and IT projects (Kütz 2007). We present a three step based life cycle model with networked elements for IT performance measurement (compare fig. 6). The model is not derived from CobiT.

\subsubsection{Cycle 1: Creating and Matching an IT Strategy}

The first cycle ensures the creating and matching of the IT strategy with the business strategy of a company. This step of matching is called IT business alignment. It assures that the results of the IT planning process (IT portfolio planning) only follows targets which have a counterpart in the business strategy. The method of IT balanced scorecard controls the compliance of key performance indicators and target values for success control. The result of the first cycle is a package of arrangements having tasks which are necessary for supporting the company's strategy.

\subsubsection{Cycle 2: Selection, Development and Roll Out of IT Applications}

After the constitution of the IT strategy and the IT portfolio, several IT projects can be defined and started. Topic of this cycle is the business oriented problem analysis and conceptual design, software development and the provision, testing and optimisation of information systems.

The challenge of IT performance measurement in this cycle is to support this process with suitable tools. IT project controlling supports the compliance of time schedules, results and budgets. The IT investment appraisal ensures the profitability analysis. Outsourcing, offshoring or nearshoring concepts allow the transfer of software development into more cost efficient countries. To minimize risks, IT performance measurement has to be involved in these processes. IT standards (e.g. life cycle models for project management, templates for projects) help to limit the costs of IT development. IT performance measurement supports the IT project manager by enforcement of standards aimed at increasing the welfare of the whole company.

The results of the second cycle are ready for running IT applications which are compliant with the company's IT strategy. They can be practised and incorporated for the daily use. 


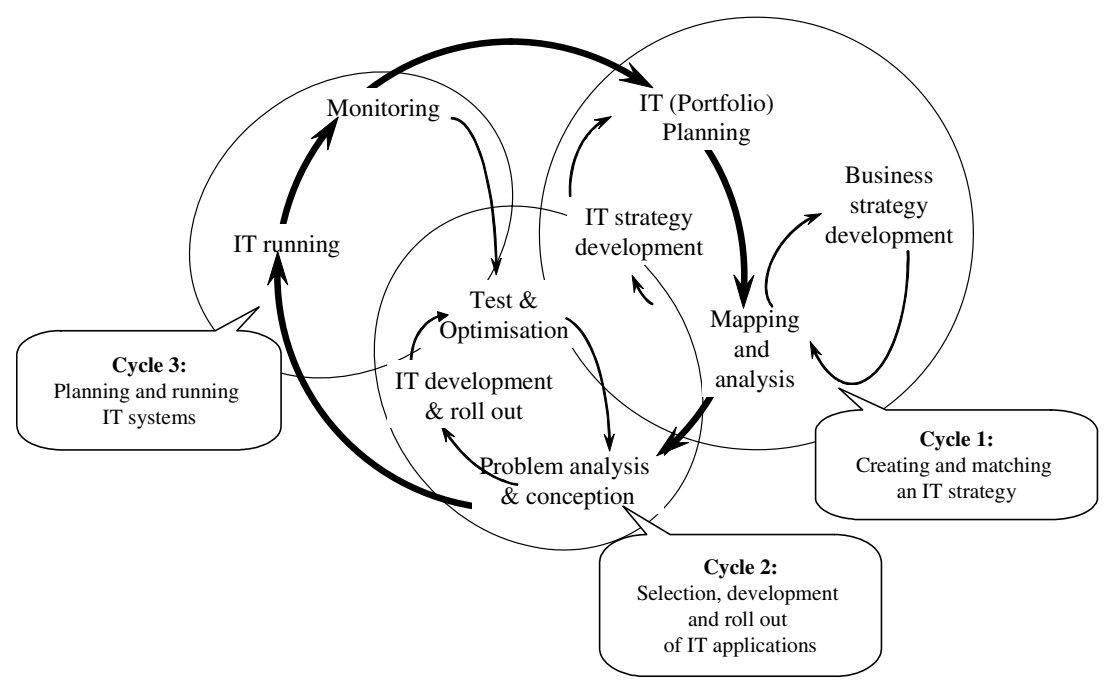

Fig. 6. Life cycle model for IT performance measurement

\subsubsection{Cycle 3: Planning and Running IT Systems}

The last cycle provides the IT infrastructure (e.g. hardware, network, ITstaff). Service level agreements help to ensure the compliance of contracts between the IT service partner (e.g. a data centre) and the IT customer (e.g. the end user). IT standards help to harmonise the IT service processes and to reduce the costs of IT ownership. Outsourcing concepts help to transfer the responsibility of IT delivery process onto the third party supplier. As a part of the monitoring, an analysis of targets and results is necessary. In case of noticeable variances, a change of the IT portfolio is necessary or a modification of the IT strategy.

\section{Case Study}

Here, we want to give a real world validation of our reference model for IT performance measurement. We describe the structure and the state of a case study, even if final results are not available yet.

\subsection{The Company}

Some people would be surprised if we take a look at the logistics company DHL for validating our SME reference model for IT performance measurement. But we will show that DHL is suitable for the validation.

DHL Express Europe operates in Europe within 31 countries generating revenue of $6.5 \mathrm{~b}$ Euro in 2008. Half of the revenue is being generated by 7 large country-wide organisations with more than $500 \mathrm{~m}$ Euro annual revenue, while the majority of the companies are medium and small and placed in small countries generating the other $50 \%$. The business model used is more or less the same in each country organisation since DHL Express Europe is providing domestic and international shipping services through a harmonised product portfolio across Europe. 
The IT cost as percentage of revenue in high revenue countries typically is lower than in small and medium sized countries. However, the IT complexity in high revenue countries is often higher due to a lower level of standardization driven through local system enhancements and unique customer requirements, and a higher volume of locally initiated projects. Smaller sized countries usually have a different IT profile since they are benefiting from a higher level of standardization supporting the business processes and a lower amount of local IT projects.

Central IT measures were in the past, often focussed on high revenue countries because their impact on the organisation is higher. These IT measures support transparency, planning of application roadmaps as well as infrastructure optimization strategies. However, these IT measures are too heavy to be implemented for smaller country organisations because the overhead with the implementation is in some case not affordable.

The IT Management of DHL Express Europe intends having IT measures in place both for larger and smaller countries. However, it appears that for smaller countries, a different approach has to be taken. Therefore, the IT management of DHL Express Europe seeks measures for smaller countries with its own set of IT measures and tools as well.

The IT organization and costs in smaller sized countries are comparable to the IT organization and costs in medium sized companies. The intent of this case study is to identify if the described approache for SME organizations can be applied in the context of smaller and medium sized organizations at DHL Express Europe and for supporting them in achieving their overall goals.

\subsection{Questions of the Management}

The IT management of DHL has raised the following questions:

1. Is the concept applicable in the context of smaller sized countries of DHL Express Europe?

2. Does the concept support achieving underlying business and IT goals (i.e. adapting the IT context in a challenging business context?)

3. Can the lifecycle drive efficiency within the IT organisation?

4. Does the concept support the IT management in their decision making process, locally as well as in the centre?

5. Does the concept increase the level of transparency?

6. Which are the possible implications for the business management?

7. Does the concept provide necessary information for IT management?

8. Which tools are necessary for the initial implementation of the cycles?

The case study has been established at the beginning of 2009 and final results are not available yet. However, the first intermediate results can be shared here:

- The transparency of the status of the local organization has been increased

- Tools are absolutely necessary to gain the full benefits and improve the ease of use

- Lack of common understanding for which detailed data was needed

- The process needs to be detailed in order to be spread across the organization 
The study is still ongoing and will provide an insight into the questions raised above.

\section{Summary and Outlook}

Small and medium enterprises (SMEs) are characterised by simple structures, high flexibility and a high sensitivity in cost management. This is the reason why IT processes in SME are lanker sized than in bigger companies. We have presented a reference model for the processes of the whole IT area. Based on this, we presented a reference model for the whole IT process life cycle of IT performance measurement which is suitable for SME because of its lankiness.

\section{References}

Becker, J., Winkelmann, A.: IV-Performance measurement. Wirtschaftsinformatik 46(3), 213221 (2004)

Bernroider, E.W.N., Hampel, A., Sumper, A.F.: An Application of the Balanced Scorecard as a Strategic IT-Performance measurement Instrument for E-Business Development. In: The Third International Conference on Electronic Business - Business Paradigms: Strategic Transformation and Partnership. Academic Publishers/World Publishing Corporation (2003)

Carr, N.G.: IT Doesn't Matter. Business Review (5), 41-49 (2003)

Carr, N.G.: Does IT Matter? Information Technology and the Corrosion of Competitive Advantage. Harvard Business School Publishing Corporation, Boston (2004)

CobiT. CobiT 4.1 Excerpt, IT Governance Institute (2008), http: / /www. isaca. org / AMTemplate. $\mathrm{cfm}$ ? Section=Downloads\&Template=/ ContentManagement/ContentDisplay . cfm\&Content ID $=34172$ (accessed May 21, 2008)

Gadatsch, A.: Grundkurs Geschäftsprozess-Management, 5th edn. Vieweg, Wiesbaden (2008)

GI. Leitbild IT-Controller/IT-Controllerin. Fachgruppe IT-Performance measurement der Gesellschaft für Informatik (2008) (in preparation)

van Grembergen, W., de Habs, S., Guldentops, E.: Structures, Processes and Relational Mechanisms for IT Governance. In: van Grembergen, W. (ed.) Strategies for Information Technology Governance, pp. 1-36. Idea Group, London (2004)

Hammer, M., Chamby, J.: Business Reengineering. Die Radikalkur für das Unternehmen, 3rd edn. Campus, Frankfurt/New York (1994)

IT Governace Institute (2008), http: / / www . itgi . com (accessed May 21, 2008)

Kaplan, R.S., Norton, P.N.: Strategy Maps: Converting Intangible Assets into Tangible Outcomes. Harvard Business School Publishing Corporation, Boston (2001)

Kütz, M.: IT-Controlling für die Praxis. dpunkt, Heidelberg (2005)

Kütz, M.: Grundelemente des IT-Controllings. Praxis der Wirtschaftsinformatik, HMD 254, 615 (2007)

Martinsons, M., Davison, R., Tse, D.: The balanced scorecard: a foundation for the strategic management of information systems. Decision Support Systems 25(1), 71-88 (1999)

Müller, A., Thienen, L.v.: E-Business-Controlling mit der Balanced Scorecard. In: Blomer, R., Bernhard, M. (eds.) Balanced Scorecard in der IT, Praxisbeispiele - Methoden - Umsetzung, Symposion Publishing GmbH, Düsseldorf, pp. 183-209 (2002) 
Meyer, M., Zarnekow, R., Kolbe, L.M.: IT-Governance Begriff, Status quo und Bedeutung. Wirtschaftsinformatik 45(4), 445-448 (2003)

Riedl, R., Kobler, M., Roithmayr, F.: Zur personellen Verankerung der IT-Funktion im Vorstand börsennotierter Unternehmen: Ergebnisse einer inhaltsanalytischen Betrachtung. Wirtschaftsinformatik 50(2), 111-128 (2008)

Schauer, H.: Vergleichende Buchbesprechung IT-Controlling. Wirtschafsinformatik 48(3), 212-218 (2006)

Weill, P., Ross, J.W.: IT Governance on One Page, Center for Information Systems Research Working Paper No. 349. MIT Sloan School of Management (2004)

Zarnekow, R., Brenner, W., Pilgram, U.: Integrated Information Management: Applying Successful Industrial Concepts in IT, pp. 39-60. Springer, Heidelberg (2006) 